\title{
Surveying effects of forward-backward P/E ratios on stock's return and fluctuation in Tehran's stock exchange
}

\author{
Younos VakilAlroaia*, Seyed Razi Nabavi and Hossin Eslami Mofidabadi
}

Department of Management, Semnan Branch, Islamic Azad University, Semnan, Iran, P.O.B: 35145-175

\begin{tabular}{l}
\hline A R T I C L E I N F O \\
\hline Article history: \\
Received December 18, 2011 \\
Received in Revised form \\
February, 28, 2012 \\
Accepted 16 April 2012 \\
Available online \\
April 18 2012 \\
\hline Keywords: \\
Stock risk \\
Sectional auto correlation \\
Forward-backward effect \\
Predictability of return
\end{tabular}
A B S T R A C T

\begin{abstract}
The aim of this study is to study the relationship between forward-backward effects on stock return, which normally depends on Price-Earnings ratio $(\mathrm{P} / \mathrm{E})$ and stock fluctuation in stock exchange. Monthly time series pattern of Tehran stock exchange are used monthly from 2006 to 2010. The data contains all available companies in exchange where the shares were traded at the least 120 days during for the recent 12 months. The results of this research show that the independent variables investigated in this research have meaningful effects on the research's dependent variable. This means that the effects of company's systematic risk and markets risk on companies' stock return are positive.
\end{abstract}

\section{Introduction}

This research surveys sources and sectional auto correlation patterns in return and stocks fluctuation, which depends on stocks' risk (portfolios) in Tehran stock exchange (TSE) and they were actively traded during the time study of this survey. Identifying important indicators for stocks expected return value is one of important issues in modern financial science. Stockholder's wealth depends on risk and return and it is not easy to determine future return, precisely (Emadzadeh et al., 2009). Researchers studied a group of indicators in different conditions and various viewpoints, but there is no agreement on a pattern, which includes all of indicators. The aim of this paper is to study forwardbackward effects, which depend on returns risk and stocks fluctuation on TSE by using conditional variance technique called GARCH $(1,1)$.

In this paper, a set of actively traded companies on TSE from the year 2006 to 2010 are considered. We assume there was no significant damage or incidents on any of these firms for the period of study. In addition, the investment companies are not considered because of special conditions of their

Corresponding author. Tel: +989122316247

E-mail addresses: younos.vakil@gmail.com (Y. VakilAlroaia) 
activities. Statistical model is based on sampling models among some qualified companies. During the past few decades, there have been many methods used to determine the information influencing on stock return. In addition to prediction of future stock return by use of time series historical data, the study identifies important indicators for future stock return and making a pattern are also major events in financial research. These indicators are called risk factors in financial literature.

There are many efforts on modeling the relationship between risk and return. The researchers gave different factors; especially beta scale resulted from model of capital asset pricing model (CAPM) (Sharpe, 1964; 2007) and three items including factorial, size scale, which show risk (Fama \& Frenchech, 1993). These studies state recognition of different viewpoints about the nature of risk but there is no agreement among them on how correctly they show all these risk factors. Still, there is a doubt about the value of some of these factors. One of these major reasons for this study is that researchers act by their self-personal view as defining and explaining financial risk and sometimes focus on factors, which have received a little importance.

\subsection{Risk and return}

The risk and return frame works are other events in this research where stock exchange expected return is measured by risk and it is necessary to identify the factors, which show risk for measuring risk. Some of these selected factors are very important such as return rate since it is a major factor and their effects are not represented in other factors, very clearly (Wang \&Tan, 2010).

\subsection{Stock market value}

Market value includes price of selling one property selling in normal business condition. From the beginning of $20^{\text {th }}$ century, some individuals who worked on stock market believed that historical prices as well as pattern of changes contain useful information about prices in future. Therefore, the pattern of changes is identified by reaching prices process and this pattern says that some times, a special process occurs (Galibaf et al., 2009; Gebka, 2008). These scholars called this "Chartist" because their focus is on pricing chart (Brennan et al., 1998). According to this theory, there is no necessary for fundamental analysis.

From the beginning of 1930, other studies started against of this viewpoint. The major focus of this research is on randomly chosen prices trends and it is based on this issue that prices do not follow from a special process. The results of these studies, which arrived in investment and economic perspectives, are in from one powerful mental and theoretical event and the hypothesis of prices randomly manner has formed. Randomly ideology is proved by experimental tests, which states that sequential changes in prices in short time periods like one day, one week or one month are independent from each other (Boudoukh et al., 1994).

\subsection{Predicted return models}

Some of predicted models of return exist in financial literature used to predict stock price movements, but there are words and variances in this model of research.

\subsubsection{ARCH auto regression model (conditional variance inconsistent) and GARCH (extended conditional variance inconsistent)}

Changes of fluctuation in financial market are shown variance inconsistent in a period of time. Different models are used for solving variance in time series and they incorporate natural features of financial markets. Arch model has most applicability among models and GARCH model is the extended ARCH model. GARCH model can solve variance inconsistent problem by evaluating 
conditional fluctuation. The survey of sectional auto-correlation natural in portfolios market was studied for developed countries and its source and the nature was defined in these markets (Ghalibaf et al., 2009).

In this study, we try to make some experimental evidence for sectional auto-correlation source and structure in available TSE to create other approved tools for helping investors and other users as adapting economical invest mental deciding. Sectional auto correlation theory is another interesting method for studying stock trend. The first study on this subject is associated with return prediction for big portfolios including companies' stock. (Lo \& MacKinlay, 2000; Chordia \& Swaminathan, 2001).

The sectional inconsistent auto-correlation structure is called as a forward-backward effect, which depends on size and related to slower adjustment of little stocks in published news in market (Badrinath et al., 1995). These findings followed with some doubts about sectional auto-correlation natural and sources against auto-correlation among returns. On one side, some people believe that forward-backward relationship proposed by Lou and MakKinely is artificial and is explainable on the basis of auto-correlation among returns (Banz, 1981; Summers \& Waldman, 1990; McQueen et al., 1996; Chang et al., 1999). Other people believed sectional auto correlation is valid and other domains of forward-backward relations except size are studied. For example, Berinan (1993) concluded that some investment analyzers obey speed of adjusting stock price in current news.

Discovering the relative importance indicating factors for expected level of stock return has been one of the interesting problems in modern finance. Many people have implemented various candidate sets of indicators from various perspectives, Wang and Tan (2008) used least angle regression (LARS) to select a sparse and relatively stable set of indicators for predicting stock return based on relative complete data from a large set of factors from US financial reports. The use of LARS was consistent with the theoretically well developed economic theory arbitrage pricing model. The results of their study offered new insights of the well-known indicators from the previous studies and discover new important factors.

Therefore, the primary objective of this paper is to survey Price-Earnings ratio (P/E)-dependent forward-backward effects on return and stocks fluctuation in TSE by use of GARCH conditional variance technique. Evaluation return and stock fluctuation in stock exchange are performed by forward-backward effects based on stocks Price-Earnings ratio $(\mathrm{P} / \mathrm{E})$. In addition, the results are compared with each other to determine the variables of return and fluctuation. Finally, evaluated GARCH model is used for forming immune portfolio and the return of this portfolio is used as a complete scale for evaluating the operation of GARCH models (Lo \& MacKinlay, 1990; Bodie, 2005; Brooks, 2009).

\subsection{Price-Earnings ratio (P/E)}

The most important financial ratios are $\mathrm{P} / \mathrm{E}$ per share. The investors mostly use $\mathrm{P} / \mathrm{E}$ ratio as a tool to show the value of a company. In TSE, P/E ratio is used as an index in addition to other methods to evaluate securities. The calculation basis of $\mathrm{P} / \mathrm{E}$ ratio in TSE is obtained by division of market total value by the total net profit after tax deduction of the listed companies (McWilliams, 1966).

\subsection{Problem statement}

The effect of markets stock exchange is an obvious work and flowing capitals and desired allocating sources is one of important duties in this market. We should find a solution for engaging investors towards investigating in financial assets and make a condition, which help investors on financial markets and their decisions. Achieving a long term and continual growth needs equipment and 
optimum allocation of resources in national economic level and this is not possible without the help of financial markets especially extended capital market. The effect of stock exchange on economical development of countries is an evident event. Following capitals and desired allocation of resources is one of major duties in this market. TSE is one of the biggest and the most important exchange among Middle East stock exchanges and it has had significant return over the past few years. Therefore, identifying effective factors on forward-backward effects, which depend on stocks risk in return and stocks fluctuation in their stock exchange is very important and has very preference in this research.

\section{Methodology}

\section{Hypothesis of research}

In this research, we survey existence or non-existence of sectional auto-correlation in TSE based on sectional auto-correlation literature using forward-backward effects and the following hypothesis is proposed:

\subsection{First hypothesis: Return on equity}

The first hypothesis is associated with the relationship between the firms with high $\mathrm{P} / \mathrm{E}$ ratios and the firms with low $\mathrm{P} / \mathrm{E}$ ratio, which is as follows,

$\mathrm{H} 1$ : The return of firms with high $\mathrm{P} / \mathrm{E}$ ratios could predict the return of the firms with low $\mathrm{P} / \mathrm{E}$ ration.

\subsection{Second hypothesis: Stock fluctuation}

The second hypothesis is associated with the effect of stock price fluctuations between stocks with high $\mathrm{P} / \mathrm{E}$ ratios and stock prices with low $\mathrm{P} / \mathrm{E}$ ratios.

$\mathrm{H} 2$ : The stock price fluctuation of the firms with high $\mathrm{P} / \mathrm{E}$ ratios can predict stock price of firms with low $\mathrm{P} / \mathrm{E}$ ratios.

In order to examine of these hypothesis, consider two portfolios $\mathrm{A}$ and $\mathrm{B}$, where the return of portfolio B can predict the return of portfolio A but the opposite does not hold, i.e. the return of portfolio A does not predict the return of portfolio B. In order to examine two proposed hypothesis, we first apply some shocks on the returns of two portfolios $\mathrm{A}$ and $\mathrm{B}$ with $\left(\mu_{B, t}, \mu_{A, t}\right)$, calculate the following regression function,

$$
\begin{aligned}
& \mathrm{R}_{\mathrm{j}, \mathrm{t}}=\alpha_{0}+\sum_{i=1}^{L} \alpha_{\mathrm{j}, \mathrm{t}} \times \mathrm{R}_{\mathrm{j}, \mathrm{t}-1}+\sum_{i=1}^{L} \alpha_{\mathrm{j}, \mathrm{t}-1}^{\prime} \times \mathrm{R}_{\mathrm{j}, \mathrm{t}-1} \times \mathrm{D}^{\mathrm{up}}+\sum_{i=1}^{L} \beta_{\mathrm{k}, \mathrm{t}} \times \times \mathrm{R}_{\mathrm{k}, \mathrm{t}-1}+\sum_{i=1}^{L} \beta_{\mathrm{k}, \mathrm{t}-1}^{\prime} \times \mathrm{R}_{\mathrm{k}, \mathrm{t}-1} \times \mathrm{D}^{\mathrm{up}}+\mu_{\mathrm{j}, \mathrm{t}}, \\
& h_{j, t}=\gamma_{0}+\gamma_{1} \times \mu_{j, t-1}^{2}+\gamma_{2} \times h_{j, t-1},
\end{aligned}
$$

where $\left(R_{j, t-i}\right)$ and $R_{k, t-i}$ are return of two portfolios with $\mathrm{K}=\mathrm{A}, \mathrm{B}$ and $\mathrm{J}=\mathrm{A}, \mathrm{B}$ at time $\mathrm{t}-1, \mathrm{D}^{\text {up }}$ is a dummy variable, which is equal to one when market is on upside and zero, otherwise. $\operatorname{GARCH}(1,1)$ is modeled with conditional variance of $h_{j, t}, \mu_{j, t}$ represents return's shock. In the next step, we preserve shocks on $V_{M, t}$, or the market portfolio using the following regression functions,

$$
\begin{aligned}
& \mathrm{R}_{\mathrm{m}, \mathrm{t}}=\sum_{i=1}^{5} \mathrm{R}_{\mathrm{m}, \mathrm{t}-1}+v_{\mathrm{m}, \mathrm{t}} \\
& \mathrm{h}_{\mathrm{m}, \mathrm{t}}=\gamma_{0}+\gamma_{1} \times v_{\mathrm{m}, \mathrm{t}-1}^{2}+\gamma_{2} \times h_{\mathrm{m}, \mathrm{t}-1}
\end{aligned}
$$


In the next stage, for portfolio $\mathrm{B}, \mathrm{J}=\mathrm{A}$, the squares of shocks with gap on other portfolio $(\mathrm{K}=\mathrm{A}, \mathrm{B})$ or $\left(\mu_{k, t-1}\right)$ which was already calculated, along with the squares of resulted residuals from returns on market, $\left(v_{\mathrm{m}, \mathrm{t}-1}^{2}\right)$ are considered as descriptive variables in conditional variance equation. The squares of the returns represent the variances of unpredicted returns of portfolio K. For the equations of variance, again, we have separated the market upside and downside conditions and the following equations are estimated.

$$
\begin{aligned}
& \mathrm{R}_{\mathrm{j}, \mathrm{t}}=\alpha_{0}+\sum_{i=1}^{L} \alpha_{\mathrm{j}, \mathrm{t}} \times \mathrm{R}_{\mathrm{j}, \mathrm{t}-1}+\sum_{i=1}^{L} \alpha_{\mathrm{j}, \mathrm{t}-1}^{\prime} \times \mathrm{R}_{\mathrm{j}, \mathrm{t}-1} \times \mathrm{D}^{\mathrm{up}}+\sum_{i=1}^{L} \beta_{\mathrm{k}, \mathrm{t}} \times \mathrm{R}_{\mathrm{k}, \mathrm{t}-1}+\sum_{i=1}^{L} \beta_{\mathrm{k}, \mathrm{t}-1}^{\prime} \times \mathrm{R}_{\mathrm{k}, \mathrm{t}-1} \times \mathrm{D}^{\mathrm{up}}+\mu_{\mathrm{j}, \mathrm{t}}, \\
& \mathrm{h}_{\mathrm{m}, \mathrm{t}}=\gamma_{0}+\gamma_{1} \times \mu_{\mathrm{j}, \mathrm{t}-1}^{2}+\gamma_{2} \times h_{\mathrm{j}, \mathrm{t}-1}+\gamma_{3} \times \mu_{j, k-1}^{3}+\gamma_{3}^{\prime} \times \mu_{j, k-1}^{3} \times D^{\mathrm{up}}+\gamma_{4} \times v_{\mathrm{m}, \mathrm{t}-1}^{2}+\gamma_{4}^{\prime} \times v_{\mathrm{m}, \mathrm{t}-1}^{2} \times D^{\mathrm{up}} .
\end{aligned}
$$

Therefore, assuming $\mathrm{J}=\mathrm{A}, \mathrm{K}=\mathrm{B}, \alpha_{A, i}$ shows autocorrelation of portfolio $\mathrm{A}$ with gap $i$ and $\beta_{B, i}$ represents sensitivity of portfolio B on A with gap $i$ and $\gamma_{3}$ shows the size of portfolio B's fluctuation on $\mathrm{A}$. If there is a forward-backward relationship between portfolio $\mathrm{A}$ and $\mathrm{B}$, we could expect the return with gap of portfolio B would be bigger than the return of portfolio A compared with the same circumstances when we have no gap. In addition, when B influences $\mathrm{A}, \gamma_{3}$ and $\left(\gamma_{3}+\gamma_{3}^{\prime}\right)$ are meaningfully not equal to zero. The hypotheses can be stated as follows,

Forward-backward effects on the return:

If there is an upward market:

$$
\begin{aligned}
& \left\{\begin{array}{l}
\mathrm{H}_{0}: \sum_{i=1}^{L}\left(\beta_{B, i}-\beta_{B, i}^{\prime}\right)=\sum_{i=1}^{L}\left(\beta_{A, i}-\beta_{A, i}^{\prime}\right) \\
\mathrm{H}_{1}: \sum_{i=1}^{L}\left(\beta_{B, i}-\beta_{B, i}^{\prime}\right) \neq \sum_{i=1}^{L}\left(\beta_{A, i}-\beta_{A, i}^{\prime}\right)
\end{array}\right. \\
& \left\{\begin{array}{l}
\mathrm{H}_{0}: \sum_{i=1}^{L}\left(\beta_{B, i}\right)=\sum_{i=1}^{L}\left(\beta_{A, i}\right) \\
\mathrm{H}_{1}: \sum_{i=1}^{L}\left(\beta_{B, i}\right) \neq \sum_{i=1}^{L}\left(\beta_{A, i}\right)
\end{array}\right.
\end{aligned}
$$

Forward-backward effects on the fluctuation:

If there is an upward market: $\left\{\begin{array}{l}\mathrm{H}_{0}:\left(\gamma_{3}+\gamma_{3}^{\prime}\right)=0 \\ \mathrm{H}_{1}:\left(\gamma_{3}+\gamma_{3}^{\prime}\right) \neq 0\end{array}\right.$ If there is a downward market: $\left\{\begin{array}{l}\mathrm{H}_{0}:\left(\gamma_{3}\right)=0 \\ \mathrm{H}_{1}:\left(\gamma_{3}\right) \neq 0\end{array}\right.$

For testing the relative hypothesis to forward-backward effect on return, the sensitivity coefficient of return of a portfolio with a gap and high-risk amount is considered to be meaningful and sensitivity coefficient of portfolio with gap and low risk amount than the current return of portfolio with high risk is not meaningful. Therefore, we can conclude that there are forward-backward effects and this relationship is asymmetrical and if it is meaningful, both sensitivity coefficients for determination of forward-backward effects of $\mathrm{Z}$ statistics will be in following form:

$$
Z=\frac{\left(\theta_{2}-\theta_{1}\right)^{-1}}{\left[\sqrt[2]{\left(\sigma_{\theta_{2}}^{2}+\sigma_{\theta 1}^{2}\right)^{1}}\right]}
$$


In this statics, $\sigma_{\theta 1}^{2}$ and $\sigma_{\theta 2}^{2}$ are the variances of $\theta_{1}$ and $\theta_{2}$ parameters and null hypothesis will be rejected if counted statics is bigger than table amounts and otherwise there is no reason for rejecting null hypothesis.

\section{3 .Population and Sample Size}

The information which are used in this research are collected by received files of stock exchange company and research and information technology management site and they are organized and calculated by excel software. Then, Eviews economic software is used for different evaluation and tests. The population of this research includes all of approved companies in Tehran stock exchange from the beginning of 2003 until the end of 2003 without considering holding firms. In addition, the companies with low trading activities were not also considered and the necessary information were gathered for 505 business days. In the next stage of sampling, the average number of companies business days were calculated and finally some companies were selected where their business day's number was more of average of companies' business companies during the year of study.

As the companies were selected in above method, two portfolio groups were formed. Two pairs of portfolio were formed for controlling the effects of size and analyzing forward-backward effects, which depends on business amount and each pair contains two portfolios with big size and different risk amount. The method of forming portfolio is as below:

First, the companies were ranked on the basis of average past year capital value and then two portfolios with big size and small size were placed. Next, companies were ranked in every one of organized portfolio based on their size and average of percent of trading and divided in two portfolios with high business amount and low Price-Earnings ratio (P/E)amount. These stocks change in every pair of portfolio on the basis of ranked scales and sampling and include new stocks annually. The size Price-Earnings ratio (P/E)portfolios were used for naming portfolios.

\subsection{The method of measuring researches variables}

First, daily return for available stocks in considered portfolio is calculated based on the following for calculating daily return of portfolio,

$$
\mathrm{r}_{\mathrm{jt}}=\log _{e}^{\left(\frac{\mathrm{p}_{\mathrm{jt}}}{\mathrm{p}_{\mathrm{jt}}-1}\right)}=\ln \left(\frac{\mathrm{p}_{\mathrm{jt}}}{\mathrm{p}_{\mathrm{jt}}-1}\right)
$$

where $p_{j t}$ is the price of stock $j$ at time $t$ and $p_{j t-1}$ is the price of stock $j$ at time $t-1$. In our proposed model, we considered equal weight for all stocks to calculate the average return as follows,

$$
r_{p}=\frac{1}{n} \sum_{j=1}^{n} r_{j t}
$$

In addition, CAPM is calculated as follows,

$$
(C A P M)=R_{i}=\beta \times\left(R_{m}-R_{f}\right)+R_{f} \Rightarrow R_{i}-R_{f}=\beta \times\left(R_{m}-R_{f}\right) \Rightarrow \beta=\frac{\left(R_{i}-R_{f}\right)}{\left(R_{m}-R_{f}\right)}=\frac{\left(K_{i}-K_{f}\right)}{\left(K_{m}-K_{f}\right)},
$$

where $R_{i}$ is the return of stock $i, R_{m}$ is the return of market, $R_{f}$ is the risk free asset. In addition, for each company we define stake $\left(S_{\text {it }}\right)$ in terms of price $\left(\mathrm{p}_{\mathrm{it}}\right)$ and capital $\left(\mathrm{cap}_{\mathrm{i}}\right)$ as follows, $S_{\text {it }}=\mathrm{p}_{\text {it }}+$ cap $_{i}$ 
Ranking companies was used as ranking scale on the basis of size of past markets value. The return of price indicator and cash return was another variable considered as market return in this study. Markets return is accounted as follow:

$$
\left.R_{\mathrm{mt}}=\log _{e} \mathrm{e}^{\frac{\text { TEDPIX }_{\mathrm{t}}}{\operatorname{TEDPIX}_{\mathrm{t}-1}}}\right)=\ln \left(\frac{\text { TEDPIX }_{\mathrm{t}}}{\text { TEDPIX }_{\mathrm{t}-1}}\right)
$$

For the proposed study we considered a dumy variable (dum) as follows,

$$
d u m=\left\{\begin{array}{lll}
1 & \text { if } \quad R_{i} \geq 0 \\
0 & \text { if } \quad R_{i}<0
\end{array}\right.
$$

\section{Empirical results}

Daily return calculated for portfolios and portfolios features are showed in Table 1.

\section{Table 1}

Summary of data statistical features for ranked portfolios on the basis of sectional auto-correlation risk in return and fluctuation

\begin{tabular}{ccccc}
\hline Portfolio & $\mu$ & S.D & SK & \multicolumn{1}{c}{} \\
\hline R11 & 8.54857214 & 0.5164804 & 0.008651 & 0.0001012 \\
R12 & 5.1211012 & 0.151022 & 0.002087 & 0.004024 \\
\hline R21 & 7.212054501 & 0.050211 & 0.00142 & 0.008084 \\
\hline R22 & 3.2645520 & 0.451956 & -0.000587 & \\
\hline
\end{tabular}

It is observed that most return is in portfolio with big size and low risk weight with (0.00142) average and the lowest return is in portfolio with big size and big risk rlweight (-0.000587). On the basis of scale deviation of portfolios return sample, it is observed that portfolio which has big size, low risk weight has the highest risk and portfolio, which has low business amount, and stocks with little size have the lowest risk. About extension scale, our results show that distribution of data more extended than normal distribution and their bake is more spreaded than normal distribution. The value of this scale for $\left(R_{12}\right)$ is higher than the rest of them. Finally, Jarakbera test rejected normally portfolios return distribution.

The results of portfolios regression which has low risk and portfolios with high risk $\left(\left(\mathrm{R}_{11}\right)\right.$ on $\left.\left(\mathrm{R}_{12}\right)\right)$ in short time and stagnation shows that there is a relationship between delayed portfolios return high business amount and portfolios current return and low businesses amount. Investigating regression coefficient with depended variable $\left(\mathrm{R}_{12}\right)$ shows portfolios delayed return with high risk amount in short term can predict portfolios with high Price-Earnings ratio (P/E)amount and portfolios with low Price-Earnings ratio $(\mathrm{P} / \mathrm{E})$ amount cannot show that past portfolios which has low Price-Earnings ratio $(\mathrm{P} / \mathrm{E})$ cannot predict current return.

In general, the results show the existence of forward-backward effects depends on short-term amount and show that these effects are one-sided. The results of regressing portfolios return with big size on portfolio with small size $\left(\left(\mathrm{R}_{11}\right)\right.$ on $\left.\left(\mathrm{R}_{12}\right)\right)$ shows that small portfolios shocks can predict unpredicted big portfolios return conditional. This relationship is meaningful for markets condition. In addition, these kinds of result are funded for regression equation with $\left(\mathrm{R}_{22}\right)$ dependent variable in conditions, which represent a high ratio of risk on the market. 
Table 2

Forward-backward relations, which depend of Price- Earnings ratio (P/E)amount

\begin{tabular}{|c|c|c|c|c|}
\hline portfolio & \multicolumn{2}{|c|}{ Large size portfolio } & \multicolumn{2}{|c|}{ Small size portfolio } \\
\hline DV. (J) & R22 & DV. (J) & $\mathrm{R} 12$ & R11 \\
\hline IDV.(J,K) & $\mathrm{R} 22 \& \mathrm{R} 21$ & IDV.(J,K) & $\mathrm{R} 11 \& \mathrm{R} 12$ & $\mathrm{R} 11 \& \mathrm{R} 12$ \\
\hline \multicolumn{5}{|c|}{ Latest Risk } \\
\hline \multicolumn{5}{|c|}{ (own-autocorrelation) } \\
\hline$\left(\alpha_{J,-1}\right)$ & $\begin{array}{c}0.604581 \\
(0000.0)\end{array}$ & $\begin{array}{c}30363320 \\
(0000.0)\end{array}$ & $\begin{array}{c}30338560 \\
(0000.0)\end{array}$ & $\begin{array}{l}441400 \\
(0000.0)\end{array}$ \\
\hline$\sum_{i=5}^{-1}\left(\alpha_{J, J}\right)$ & $\begin{array}{l}0.542556 . \\
(0.52314)\end{array}$ & $*$ & $*$ & $*$ \\
\hline \multicolumn{5}{|c|}{ (cross-autocorrelation) } \\
\hline$\left(\beta_{k-1}\right)$ & * & $\begin{array}{c}0.321545 \\
(0.1250)\end{array}$ & $\begin{array}{l}0795770 . \\
(0.32165)\end{array}$ & $\begin{array}{c}1026770 . \\
(0.4512)\end{array}$ \\
\hline$\sum_{i=5}^{-1}\left(\beta_{k, J}\right)$ & $*$ & $*$ & $*$ & $*$ \\
\hline \multicolumn{5}{|c|}{ Z-STAT $=(-0.254550)$} \\
\hline \multicolumn{5}{|c|}{ Highest Risk } \\
\hline \multicolumn{5}{|c|}{ (own-autocorrelation) } \\
\hline$\left(\alpha_{J,-1}+\alpha_{J,-1}^{\prime}\right)$ & $*$ & $\begin{array}{c}0.40282 \\
(0.120958)\end{array}$ & $\begin{array}{c}0.01339301 \\
(0.05021)\end{array}$ & $*$ \\
\hline$\sum_{i=5}^{-1}\left(\alpha_{J}+\alpha_{J}^{\prime}\right)$ & $*$ & $*$ & $*$ & $\begin{array}{c}0.4129410 \\
(0.0842001)\end{array}$ \\
\hline \multicolumn{5}{|c|}{ (cross-autocorrelation) } \\
\hline$\left(\beta_{k,-1}+\beta_{k,-1}^{\prime}\right)$ & $*$ & $*$ & $*$ & $*$ \\
\hline$\sum_{i=5}^{L}\left(\beta_{k}+\beta_{k}^{\prime}\right)$ & $*$ & $*$ & $*$ & $*$ \\
\hline \multicolumn{5}{|c|}{ Variance } \\
\hline$\gamma_{3}$ & $\begin{array}{l}0.3215451 \\
(0.025458)\end{array}$ & $\begin{array}{c}0.0415555 \\
(0.0503)\end{array}$ & $\begin{array}{c}0.02541818 \\
(0.021542)\end{array}$ & $\begin{array}{c}0.0352102 \\
(0.00821589)\end{array}$ \\
\hline$\left(\gamma_{3}+\gamma_{3}^{\prime}\right)$ & $\begin{array}{c}0.045123 \\
(0.325125)\end{array}$ & $\begin{array}{c}-0.621250 \\
(0.8751484)\end{array}$ & $\begin{array}{c}0.00342187 \\
(0.521466)\end{array}$ & $\begin{array}{c}0.021541 \\
(0.3203259)\end{array}$ \\
\hline Adj.R2 & 0.354876 & 0.2597 & 0.35148 & 0.5843526 \\
\hline DW & 4.5484505 & 2.025215 & 3.01210254 & 4.215555287 \\
\hline Prob(F-STAT) & $*$ & $*$ & $*$ & * \\
\hline Prob (LM-test) & 0.936245 & - & - & - \\
\hline NOB & 329 & 329 & 548 & 548 \\
\hline
\end{tabular}

\section{Conclusions}

In this paper, we have presented an empirical investigation to study the effects of $\mathrm{P} / \mathrm{E}$ ratios of a groups of stocks on market. Based on the results of our survey, we can conclude that the evidences resulted from sectional auto-correlation in stock exchanges return and fluctuation as a new market is weaker than developed market. One of these events is associated with limitations on daily price in 
TSE. However, the same policy decreases the amount of risk fluctuation and results in fixing stocks prices but restrict the complete and fast reflection of information in prices and risks amount. Finally, we can say that TSE is not efficient in work level because $\mathrm{P} / \mathrm{E}$ ratios amount contain valuable information about stocks return and because there are weak evidences about auto-correlation in TSE. This paper can be future extended for a more comprehensive study where a more time-window with a longer time horizon, which helps find more realistic results and we leave it for interested researchers as possible future works.

\section{Acknowledgment}

The authors would like to thank the anonymous referees for their comments on this paper specially the comments of the second referee, which was almost as long as the original paper.

\section{References}

Badrinath, S.G., Kale, J.R., Neo, T.H. (1995). Of shephard, sheep, and the cross-autocorrelations in equity returns. Review of Financial Studies, 8, 401-430.

Banz, R.W. (1981). The relationship between return and market value of common stocks. Journal of Financial Economics, 9, 3-18.

Bodie, Z. (2005). Investments. Boston, Mass:McGraw-Hill Irwin.

Boudoukh, J., Richardson, M.P., \& Whitelaw, R.F. (1994). A tale of three schools: insights on autocorrelations of short horizon stock returns. Review of Financial Studies, 7, 539-573.

Brooks, C. (2008). Introductory to Financial Markets. Cambridge University Press, $2^{\text {nd }}$ ed.

Brennan, M.J., Choridia, T., \& Swamminathan, B. (1998). Alternative actor specification security characteristics and the cross-section of stock return. Journal of Financial Economics, 49, 345-373.

Chang, E. C., McQueen, G.R., \& Pinegar, J.M. (1999). Cross-autocorrelation in Asian stock markets. Pacific-Basin Finance Journal, 5, 471-493.

Chordia, T., \& Swaminathan, B. (2001). Trading volume and cross-autocorrelations in stock returns. Journal of Finance, 55, 913-935.

Emadzadeh, M.K., Zareie, F., \& Toresian, A. (2009). Indicators of Micro and macro effective on stock exchange. Journal of Auditing, Isfahan University.

Gebka, B. (2008). Volume-and size-related lead-lag effects in stock returns and volatility: An empirical investigation of the Warsaw stock exchange. International Review of Financial Analysis, $17(1), 134-155$.

Ghalibaf, A.H., Asmaeli, A., \& Bagheri, A. (2009). The study of forward-password in size and pulsation of Tehran stock exchange. Research Finance, 1, Spring and Summer.

Fama Eugene, F., \& Kenneth. R. F. (1993). Common risk factors in the returns on stocks and bonds. Journal of Financial Economics, 33, 3-56.

Lo, A, \& MacKinlay, A.C. (1990). When are contrarian profits due to stock market overreaction? Review of Financial Studies, 3, 175-205.

McQueen, G., Pinegar, M., \& Thorley, S. (1996). Delayed reaction to good news and crossautocorrelation of portfolio returns. Journal of Finance, 51, 889-920.

Rahmani, A., \& Saeedi, F. (1998). The evaluation of logit model function in predicate of stock exchange. Journal of Stock Exchange, 1(2), 43-85.

Saey, M.J., Asmaeli, A., Bagheri, A. (2010). Empirical research on net profit in some companies. Journal of Knowledge and Development, 17, 30.

Sharpe, W.F. (1964). Capital asset prices: A theory of market equilibrium under conditions of risk. Journal of Finance. 19(3), 425-442.

Summers L, \& Waldman R. (1990). Noise-trader risk in financial markets. Journal of Political Economy 98(4), 703-738. 
1740

Sharpe, W.F. (2007). Investors and Markets: Portfolio Choices, Asset Prices, and Investment Advice. Princeton: Princeton University Press.

Wang, Z., \& Tan, S.H. (2010). Identifying idiosyncratic stock return indicators from large financial factor set via least angle regression. Expert Systems with Applications, 36(4), 8350-8355. 